\title{
Length of Online Course and Student Satisfaction, Perceived Learning, and Academic Performance
}

\author{
Janet M. Ferguson \\ Canisius College, USA
}

\author{
Amy E. DeFelice \\ City University of New York (CUNY) Graduate Center, USA
}

\begin{abstract}
This research presents findings from a two-part study. In the first part, graduate students taking online courses were given a course evaluation form. Student responses from online abbreviated summer sessions were compared to student responses from online full-semester courses.

Both the intensive and full-semester courses were taught by the same professor and both had identical requirements in terms of assignments and exams. The independent variable was the length of time taken to complete the requirements, with the dependent variables being satisfaction with the course, perceived learning, and academic performance. A statistical analysis of the data found significant differences in a number of areas.
\end{abstract}

Keywords: Online learning; course format; graduate school; course satisfaction; communication; academic performance; five-week intensive course; full-semester course; massed vs. distributed learning; equivalency theory

\section{Introduction}

Online education continues to grow and the expansion has touched all areas of education, from grade school to graduate school. Online learning has become a mainstream tool in education (Harden, 2002). In surveying more than 1,000 colleges and universities, The Sloan Consortium found that increasing numbers of postsecondary institutions consider online learning as part of their long-term strategy. According to the Consortium report, $56 \%$ of institutions included online learning in their strategic plans in 2005, as compared to $49 \%$ in 2003 . Enrollment in online courses and programs continues to increase. In 2005, online course/program enrollment grew by 18.2\%. This exceeds overall higher education course enrollment growth and also exceeds - by 10 times - the online course enrollment growth projected by the National Center for Education 
Statistics (Allen \& Seaman, 2005). According to some educators, online learning is one of the most important and significant new instructional approaches available for improving teaching and learning in schools today (Blomeyer, 2002). Seok (2007) claims that "elearning” is the pedagogy for new learning in the $21^{\text {st }}$ century. Improved technology has enabled instructors to design and implement online courses, using advanced techniques that are now available. However, not all online courses are designed the same way; thus, it is difficult to characterize a typical online program (Rovai \& Barum, 2003). An online program can be based on traditional lecture courses, or be self-paced, with limited or extensive interactions. Or, as in this study, the course format could be a traditional full semester or an intensive five-week summer session. Many graduate-level teacher education programs are providing students with the option of a "fast-track" to certification by offering condensed five-week courses during the summer. Seamon (2004) says "as education researchers seek to increase the body of knowledge about effective teaching and learning, it is important not to neglect a critical variable in the instructional equation: course format.”

According to some researchers, student satisfaction with the type of course delivery is determined by the degree of structure in the course (Stein, 2004). According to Stein, all of the components defining structure, such as clearly defined objectives, assignments, and deadlines, need to be present in order to increase student satisfaction.

In another study, Drennan, Kennedy, and Pisarski (2005) found that student satisfaction is influenced by positive perceptions towards technology and by an autonomous learning mode. They also found that the personality characteristics that the student brings to the course, such as an internal locus of control, can have a direct effect on satisfaction with the course.

According to Watson and Rutledge (2005), the most often cited reason for students enrolling in an online course was a "time frame most suitable for their own circumstance," (i.e., convenience). Coursework could be completed at home, after work, or after caring for a family. Travel expenses, a growing concern because of increasing gasoline prices, are eliminated, and so is time spent travelling. Accordingly, the convenience of an online course impacted student satisfaction levels with the course.

Car (2000) offers another viewpoint and suggests that not all online courses are equally effective because of differences in course design. Student satisfaction, as reflected in course completion rates, is heavily influenced by interaction between instructor-student and between student-student. Frederickson et al. (2006) reported that interaction with the teacher is the most significant contributor to perceived learning and that students who feel they have not had adequate access to their instructors are also less satisfied with the course. The study done by Watson and Rutledge (2005) found that $30 \%$ of the students disagreed with the statement, "I felt as much a part of my online class as a regular class,” indicating a degree of dissatisfaction with the interactions. This may mean that there was a certain feeling of apartness or disconnection in the online class.

Jung, Choi, Lim, and Leem (2002), when researching different types of online interactions and their effect on satisfaction with the course, found that the learners' satisfaction was more strongly 
related to the amount of student-student interaction than to the interaction with the instructor. They found that the students who collaborated with each other (i.e., to problem solve on a discussion board) expressed the highest level of satisfaction. A more recent study by Nummenmaa (2008) found that visible collaborative activities in a web-based learning environment impacted students' reaction to the course. They maintained that "lurkers," or those who did not actively participate in the course, had more negative emotional experiences with the course than those who interacted collaboratively. All of these studies indicate that connectedness to the course, either by participating collaboratively with other students or by interacting with the professor, will likely impact student satisfaction and that online courses offer the additional challenges and opportunities associated with not being physically connected to the class.

According to equivalency theory (Simonson, Scholosser, \& Hanson, 1999), course learning experiences should be constant regardless of delivery method. The basic premise of equivalency theory is that learning experiences for both local, or face-to-face learners, and distant, or online learners, should be designed in order to provide equivalent learning for both groups of students. The research of Lapsley, Moody, and Arbaugh (2008) supports equivalency theory in terms of online and face-to-face instruction. They found that online and face-to-face instruction provides equivalent learning opportunities for students. Although equivalency theory is used to determine equivalent value of the experiences of face-to-face and online learners, in this study equivalency theory was used to determine if equivalency was met for students in five-week online courses compared to students in fifteen-week online courses. This study examined whether there were differences in online student satisfaction, perceived learning, and performance when course content and teaching pedagogy remained the same but the two courses differed in length: one was a five-week, intensive online course and the other was a fifteen-week, full-semester online course.

Many studies involving distance education have focused on comparing the academic performance and effectiveness of an online course to the academic performance and effectiveness of a traditional, face-to-face course. Some studies have compared student satisfaction with an online course versus student satisfaction with a traditional course. The authors were unable to locate any study that researched student satisfaction with a full-semester online course compared to student satisfaction with an intensive, five-week online course.

Studies on the benefits of distributed versus massed learning go back to as early as 1885 to the work on memory by German psychologist Hermann Ebbinghaus. Distributed learning is learning that occurs in smaller pieces over a longer period of time. Massed learning is learning that is condensed into one time period, such as "cramming” for a test. Distributed learning is more effective for long-term memory. In the 1980's, there was considerable research done on massed versus distributed learning in a face-to-face, traditional classroom setting. Seamon (2004) found that students in a shortened, intense, face-to-face course academically outperformed students in a full-semester, face-to-face course. He conducted a study that examined the long-term effects of different instructional formats and found that students' performance in an intensive course, meaning a course that was shorter than a full semester, was superior initially, but in post-testing three years later the full-semester students outperformed the intensive course students. Anastasi (2007) found that academic performance was similar in summer face-to-face and full-semester 
face-to-face courses. According to Anastasi, studies of face-to-face courses suggest that, contrary to previous research, students tend to perform as well in abbreviated courses, and the belief that shortened courses are somehow inferior to full-semester courses is unfounded. Earlier research by Bohlin and Hunt (1995) found that student attitudes in a face-to-face traditional format course were more positive than student attitudes in an intensive shortened face-to-face format.

The pedagogical issues associated with a shortened format versus a full-length format include the effect of different strategic approaches. The attitude of the instructor was found to be crucial to the success of intensive courses (Brett, 1996). This has been confirmed in more recent studies, which have found that a lively, engaging teaching strategy is necessary to keep the intensive course students focused (Scott, 2003). In addition, some early studies found that intensive course instructors were more likely to use class discussion instead of lectures, as well as different textbooks, tests, quizzes, and term papers (Allen et al., 1982). Allen maintained that the differences in teaching strategies would likely have an effect on the success of an intensive course.

If the metaphor is correct that education is the delivery of information, then the Internet may be the most efficient method for delivering information in terms of speed and convenience (Gordon, 2000). One may also conclude that a five-week course is a more efficient delivery format than a fifteen-week course. Another metaphor, mentioned by Gordon, is that the student is a consumer; from this perspective, students will be attracted to a program (or format) that will accomplish what they need in the shortest amount of time. If our current pedagogy is largely a product of pragmatic constraints, such as time, class size, and linear textbooks, then the pedagogy of a fiveweek course might need to be considerably different than a fifteen-week course simply because of the time factor. This raises the question of whether students are learning the content to the same degree in the different formats. In this study, the authors found that students learned the same content in the five-week and fifteen-week courses; thus, equivalency theory was supported.

All of the existing research has focused on intensive versus semester length courses in a traditional classroom setting. There is no current research on the impact of the format (i.e., shortened vs. full-term) of online courses on student satisfaction or academic performance.

\section{Purpose of the Study}

The first part of this study will compare the shortened and full-length course formats based on students' satisfaction with the interaction in the course and their intention to take online courses in the future. The second part of the study will compare students' academic performance in an intensive online course to students' academic performance in a full-semester online course. 
The research questions are as follows:

1. Is there a difference in students' satisfaction with communication between a five-week online course and a full-semester online course?

2. Will students in a five-week online course be more or less likely than students in a fullsemester online course to take another online course?

3. Is there a difference in students' perceived learning between a five-week online course and a full-semester online course?

4. Do graduate students enrolled in a five-week online course show similar student learning when compared to graduate students in a full-semester online course, as demonstrated by academic performance?

\section{Methodology}

At this medium-sized, liberal arts institution, most graduate students enroll in five-week summer sessions to complete their master's degree in one year. The five-week intensive courses are only offered during the summer. Many of these students want to take at least one course online because of the convenience.

Graduate students enrolled in the online course for pre-service teachers, Test, Measurement and Statistics, were asked to complete an online course evaluation survey at the end of the course. The platform used to teach the web-based course was the Blackboard learning management system, which allowed interaction through discussion boards, email, and chat rooms. The discussion board and email were the prime means of communication for the courses being studied.

A total of 75 students from four consecutive semesters completed the 15-question Likert scale survey, which also allowed individual comments. One of the courses was taught as an intensive five-week session and three of the courses were taught as full fifteen-week sessions. The same instructor taught all the courses, and the course requirements, including tests and assignments, were identical. The teaching strategy was identical for the two formats. The instructor attempted the same pedagogical approach in all of the courses in order to compare student satisfaction within the context of the course format.

The survey consisted of a 4-point rating scale, ranging from 1 (strongly disagree), 2 (disagree), 3 (agree), and 4 (strongly agree). The survey was designed as a 4-point scale to eliminate a neutral, or fence-sitting, option. The reliability of the survey was determined to be .77, using Cronbach's Alpha, which indicates an acceptable degree of internal consistency for this instrument.

In the second part of the study, final grades from a total of 114 students were analyzed from three summer sessions and four full-semester sessions. A compilation of students' grades from two tests and three assignments were used to compare academic performance. The assignments and the tests were weighted equally at $20 \%$ each. For the first assignment, students used SPSS (Statistical Package for the Social Sciences) to analyze two sets of test scores and they wrote a 
paper interpreting the results. For the second assignment, the students made up a test in their content area and grade level, including all of the different types of test questions and a scoring guide. The last assignment required students to select a standardized test in their content area, to critique the test's validity and reliability, using BMMY (Buro’s Mental Measurement Yearbook), and to state whether they would use it to evaluate their students. All of the assignments were sent electronically to a digital drop box. The tests consisted of a midterm test and a final test. Both were given online on a specific day, with a two-hour time limit. The final test required an understanding of previously learned material, but it was not cumulative.

\section{Hypotheses}

1. Students in an intensive five-week online course will have different satisfaction with course communication and interaction than students in a full-semester online course.

2. Students in an intensive five-week online course will have different satisfaction levels than students in a full-semester online course, as indicated by their intention to take online courses in the future.

3. Students' perceived learning will be different in the intensive five-week online course than in the full-semester course.

4. There will be differences in students' academic performance levels in the intensive five-week online course versus the full-semester course.

\section{Results}

SPSS was used to analyze the data. Table 1 summarizes the findings of individual scales according to course format and semester. 
Table 1

Mean Scores for Both Regular and Intensive Online Courses

\begin{tabular}{|l|c|c|c|c|c|c|c|c|}
\hline & \multicolumn{2}{|c|}{$\begin{array}{c}\text { Summer } \\
\text { five-week }\end{array}$} & \multicolumn{2}{c|}{$\begin{array}{c}\text { Spring } \\
\text { full-semester }\end{array}$} & \multicolumn{2}{c|}{$\begin{array}{c}\text { Fall } \\
\text { full-semester }\end{array}$} & \multicolumn{2}{c|}{$\begin{array}{c}\text { Spring } \\
\text { full-semester }\end{array}$} \\
\cline { 2 - 10 } & \multicolumn{2}{|c|}{$\mathbf{n = 2 9}$} & \multicolumn{2}{c|}{$n=\mathbf{1 4}$} & \multicolumn{2}{c|}{$\mathbf{n = 1 2}$} & \multicolumn{2}{c|}{$\mathbf{n = 2 0}$} \\
\cline { 2 - 10 } & MEAN & $S D$ & MEAN & SD & MEAN & SD & MEAN & $S D$ \\
\hline $\begin{array}{l}\text { Communicated } \\
\text { with classmates }\end{array}$ & 3.00 & 1.02 & 2.85 & .555 & 2.92 & .515 & 2.90 & .788 \\
\hline $\begin{array}{l}\text { Communicated } \\
\text { with professor }\end{array}$ & 2.6 & 1.07 & 3.21 & .893 & 3.17 & .389 & 3.40 & .754 \\
\hline Would take again & 3.4 & .884 & 3.14 & 1.03 & 3.17 & .937 & 3.75 & .444 \\
\hline $\begin{array}{l}\text { Perceived } \\
\text { learning }\end{array}$ & 3.2 & .608 & 3.21 & .579 & 3.17 & .577 & 3.55 & .686 \\
\hline
\end{tabular}

A $t$ test was used to determine whether there were significant differences in student satisfaction with communication and interaction between the five-week session and the full-semester session. It was found that students in the intensive five-week course showed higher satisfaction with student-student communication than students in the full-semester courses $(t=4.09, p=.026)$. Interestingly, the students in the full-semester session showed higher satisfaction with studentprofessor communication $(t=6.79, p=.007)$. See Table 2 .

Table 2

Students' Satisfaction and Perceived Learning

\begin{tabular}{|l|c|c|c|}
\hline & $\boldsymbol{t}$ & $\boldsymbol{d} \boldsymbol{f}$ & Significance \\
\hline $\begin{array}{l}\text { Communicated with } \\
\text { classmates }\end{array}$ & 4.09 & 112 & .026 \\
\hline $\begin{array}{l}\text { Communicated with } \\
\text { professor }\end{array}$ & 6.79 & 112 & .007 \\
\hline $\begin{array}{l}\text { Would take another } \\
\text { online course }\end{array}$ & -.150 & 112 & .890 \\
\hline Perceived learning & .542 & 112 & .625 \\
\hline
\end{tabular}

There were no significant differences between the full-semester students and the five-week students in terms of their intention to take another online course in the future. Perceived learning was higher overall in the full-semester courses than in the intensive five-week course; however, the differences were not found to be significant. 
Using the $t$ test for equality of means the overall mean final grade for the students in the fiveweek courses was found to be significantly higher than the mean final grade for the students in the full-semester courses $(t=2.35, p=.02)$. See Table 3 .

Table 3

Student Performance

\begin{tabular}{|l|l|l|l|l|l|c|}
\hline & $\boldsymbol{N}$ & Mean & $\boldsymbol{S D}$ & $\boldsymbol{t}$ & $\boldsymbol{d f}$ & Significance \\
\hline $\begin{array}{l}\text { Full } \\
\text { semester }\end{array}$ & 76 & 87.32 & 6.4 & & & \\
\hline \multicolumn{2}{|l}{} & & & -2.35 & 112 & .021 \\
\hline $\begin{array}{l}\text { Summer } \\
\text { semester }\end{array}$ & 38 & 90.01 & 4.14 & & & \\
\hline
\end{tabular}

\section{Discussion}

In terms of student satisfaction with the intensive versus the full-semester format, the findings showed two differences, both involving satisfaction with communication. Students in the intensive course were less satisfied with their communications with the instructor than the fullsemester students were. However, students in the intensive course were more satisfied with communications with other students than the full-semester students were. This aligned with hypothesis one.

In a five-week session, the burden on the professor to keep track of every email and to respond to every discussion board entry is, from experience, much more intense and demanding than if the communications were spread out over a whole semester. This might in part explain the significant difference between students' satisfaction with communications with their professor in a five-week course versus a full-semester course. In a five-week course, the professor might be overwhelmed and overburdened with a constant barrage of emails and questions, and oversights might occur unintentionally. Students may have relied on each other to a greater degree in the intensive course using the discussion board and/or email. According to Keller (2010), and his model of motivational design, satisfaction is an important component for promoting and sustaining motivation in the learning process. Keller maintains that providing feedback and reinforcement is important to motivation and thus to satisfaction. The five-week online course in which students were less satisfied with communications with the professor fits the model of motivational design in that less feedback and reinforcement were being provided by the professor in the shortened course.

There are some pedagogical advantages of online education. According to Gordon (2000), the time constraints of a traditional classroom prevent full participation of all the students, especially if the class is very large. In an online class, participation is not limited and everyone can join in a discussion at any time. If, as Gordon states, the quantity of communication in an online course is 
greater, then one wonders if the quantity of communication in a full-semester online course would be greater than in a five-week course because there is more time to interact. This could, in part, explain the greater satisfaction with communication with the professor in a full-semester course.

It was hypothesized that students in an intensive five-week course would indicate different levels of perceived learning and different satisfaction levels than the full-semester online students. Perceived learning was lower for students in the five-week session, but not significantly so. Thus, hypothesis three was not supported. Also, there were no significant differences in satisfaction levels as indicated by intent to take future online courses. Thus, hypothesis two was not supported. However, significant differences were found in academic performance, with students in the five-week session showing stronger academic performance than the full-semester students, thus supporting hypothesis four. This could be explained, in part, by the intense nature of a condensed course, where students must be focused and "on-task" continuously, with no breaks. The learned material would be fresh in the students' minds with perhaps better recollection during testing.

This study offers several useful findings, with implications for teaching in both formats. First, effective communication between students and instructors is vital to a successful online course. The teaching strategies of the online instructor need to include a variety of ways to allow this communication to occur, especially in the five-week intensive course, where the student must remain continuously focused. A pedagogical shift is needed in the five-week course to emphasize interaction with the professor. Live chat rooms, threaded discussions, and the use of blogs, combined with prompt responses to all email inquiries, are strategies that would provide opportunities for increased interaction. Other techniques to help with the intense workload would be to use recorded podcasts and Frequently Asked Questions (FAQs). These techniques could be used in the full-semester course as well, but an emphasis on instant responses would not be as critical. In an intensive course, the professor needs to be available to respond promptly to online inquiries. Another possible pedagogical change could be to make attendance in the chats and participation in the discussions mandatory, as well as to grade the quality of participation, which would motivate students to be actively involved. Participation was not graded in either the fullsemester or the five-week course; however, an assumption is made that this strategy would help the students in the full-semester course to feel more connected to their classmates.

This research has broken new ground in the study of online learning in that it is the first to explore how different formats (full-semester versus five-week shortened courses) influence student attitudes and academic performance. As online course offerings expand, the more we know about concentrated online courses, the better we can address student learning. This research may have implications for an institution's policies for determining the length of online courses.

A limitation of this study involves the type of student. The summer session student may be different from a full-semester student, for example full-time versus part-time, older versus younger, higher or lower GPA, personality characteristics, and general expectations from the 
course. These variables were not explored in this study and raise questions for future research. The findings from this study are also limited by the fact that certain factors could not be controlled and this was not a random sample. Students' personalities and predispositions could affect responses, as well as their familiarity with technology and their background in the subject being studied. One suggestion to ensure familiarity with the technology would be to require all students to complete an online informational workshop that explains how to use drop boxes, chat rooms, etc. This study should be repeated with a larger number of students in the sample.

Another question that needs to be addressed includes a study of the number of students in the online course, or class size, and how this effects satisfaction, perceived learning, and actual academic performance. Students' level of participation in the discussion boards and chat rooms on Blackboard could also be compared to their satisfaction with their connection to the professor and to other students. Additionally, future research should include studies comparing retention of learning between intensive and full-semester students.

Some of the findings from this study support equivalency theory in that perceived learning and overall satisfaction were not significantly different for the five-week intensive course and the fullsemester course. This indicates that students had equivalency of perceived learning experiences in both the intensive and the full-semester courses. In addition, this study found that students' satisfaction with a five-week session when compared to a full-semester session, in a number of areas, was similar but that effective, meaningful communication both student-to-student and student-to-professor is key to a successful online course, regardless of format. Significant differences in satisfaction with student-student and student-professor communications between the five-week session and full-semester session suggests that different pedagogical approaches must be considered. Although different pedagogical considerations must be made for the different course formats, equivalent learning is possible. Benefits of this study include informing professors who are teaching five-week online summer session courses that their pedagogical approach should be different than the approach they use for a full-semester online course. 


\section{References}

Allen, I., \& Seamon, J. (2005). Growing by degrees: Online education in the United States. Needham, MA: The Sloan Consortium.

Allen, J.L., Miller, T.A., Fisher, B.L., \& Moriarty, D.D. (1982). A survey of January interim psychology courses. Teaching of Psychology, 9(4), 230-321.

Anastasi, J.S. (2007). Full semester and abbreviated summer courses: An evaluation of student performance. Teaching of Psychology, 34(1), 19-22.

Blomeyer, R. (2005). Virtual school and e-learning in K-12 environments: Emerging policy and practice. North Central Regional Educational Laboratory, Policy Issues, 11, 1-12.

Bohlin, R.M., \& Hunt, N.P. (1995). Course structure effects on students' computer anxiety, confidence and attitudes. Journal of Educational Computing Research, 13(3), 263-270.

Brett, M. (1996). Teaching extended class periods. Social Education, 60(2), 77-79.

Carr, S. (2000). As distance education comes of age, the challenge is keeping the students. Chronicle of Higher Education, 46(23), A39-A41.

Drennan, J., Dennedy, J., \& Pisarski, A. (2005). Factors affecting student attitudes toward flexible online learning in management education. The Journal of Educational Research, 98(6), 331-338.

Ebbinghaus, H. (1885/1962). Memory: A contribution to experimental psychology. New York: Dover.

Fredericksen, E., Pickett, A., \& Shea, P. (2006). Student satisfaction and perceived learning with on-line courses: Principles and examples from the SUNY learning network. Journal of Asynchronous Learning Networks, 4(2), 2-31.

Gordon, O.E., (2000). Pedagogical issues in internet education. Southern Utah University. http://aabss.org/journal2000/f10Gordon.jmm.html.

Harden, R.M. (2002). Myths and e-learning. Medical Teacher, 24(5), 469-472.

Jung, Il, Choi, S., Lim, C., \& Leem, J. (2002). Effects of different types of interaction on learning achievement, satisfaction and participation in web-based instruction. Innovations in Education and Teaching International, 39(2), 153-162.

Keller, J. (2010). ARCS model of motivational design. Retrieved from http://www.learning-theories.com/kellers-arcs-model-of-motivational-design.html. 
Lapsley, R., Kulik, B., Moody, R., \& Arbaugh, J.B. (2008). Is identical really identical? An investigation of equivalency theory and online learning. The Journal of Educators Online, 5(1).

Nummenmaa, M., \& Nummenmaa, L. (2008). University students emotions, interest and activities an a web-based learning environment. British Psychological Society, 78(1), 163-178.

Rovai, A.P., \& Barnum, K.T. (2003). On-line course effectiveness: An analysis of student interactions and perceptions of learning. Journal of Distance Education, 18, 57-73.

Scott, P.A. (2003). Attributes of high-quality intensive courses. New Directions for Adult and Continuing Education, 97, 29-38.

Seamon, M. (2004). Short and long-term differences in instructional effectiveness between intensive and semester-length courses. Teachers College Record, 106(4), 852-874.

Seok, S. (2007). eTeacher's role and pedagogical issues in elearning. World Conference on EDMEDIA, 2627-2630, Chesapeake, VA.

Simonson, M., Schlosser, C., \& Hanson, D. (1999). Theory and distance education: A new discussion. American Journal of Distance Education, 13, 60-75.

Stein, D. (2004). Student satisfaction depends on course structure. Online Classroom, 4-5.

Watson, S.W., \& Rutledge, V.C. (2005). Online course delivery and student satisfaction. ERIC document ED490363.

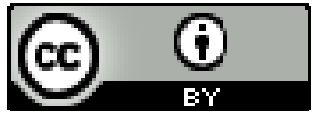

